\title{
Effect of the Embryo Genotype on the Chilling Requirement for Overcoming Peach Seed Dormancy प
}

\author{
C.H. Bruckner, J. Osmar da C. e Silva \\ and C.D. Cruz \\ Universidade Federal de Viçosa \\ 36570-000 Viçosa \\ MG Brazil
}

\author{
A. Wagner Júnior \\ Universidade Tecnológica Federal do Paraná \\ 85660-000 Dois Vizinhos \\ PR Brazil
}

\author{
M.A. Moreno Sánchez \\ Estación Experimental de Aula Dei-CSIC \\ Apdo. 13034 \\ 50080 Zaraoza \\ Spain
}

Keywords: Prunus persica, selection, stratification

\begin{abstract}
Peach seeds need chilling temperatures to overcome dormancy. The physiological bases of peach seed dormancy and bud break chilling requirement are considered strongly related, and this relationship could be used for early selection of low chilling genotypes. Peach seeds germinated more quickly under alternating than under constant temperatures. We studied the effect of the embryo genotype on the chilling requirement for seed germination. The seeds evaluated were obtained from the low chilling peach 'Campinas-1', which was either open-pollinated or crossed with the high chilling cultivar 'Miraflores'. The open pollinated 'Campinas-1' trees were surrounded by low or very low chill cultivars. The seeds (without the endocarp) were conditioned in sealed, transparent, polyethylene bags containing moist germination paper. The bags were placed in the dark in a growth chamber that alternated between 5 and $10^{\circ} \mathrm{C}$ every two days. Germination percentages were grouped into four-day classes. Seeds of open-pollinated 'Campinas-1' began to germinate twenty days after stratification and reached about $80 \%$ germination in the following two days. The germination of 'Campinas-1' $\times$ 'Miraflores' seeds began after 25 days of stratification, reaching $80 \%$ after 40 days of stratification. The seeds of the open-pollinated 'Campinas-1' germinated over a short period of time (from the $20^{\text {th }}$ to the $27^{\text {th }}$ day), whereas the hybrid seeds had a wider interval of germination time $\left(24^{\text {th }}\right.$ to $47^{\text {th }}$ day), showing the quantitative effect of the seed dormancy trait. The results indicate a strong effect of embryo genotype on the chilling requirement of the seeds, encouraging the selection of low chilling requirement genotypes based on seed dormancy. The alternation of temperatures favourable for overcoming dormancy with temperatures favourable for seed germination can be useful to screen genotypes with fewer differences in chilling requirement.
\end{abstract}

\section{INTRODUCTION}

Peach seed dormancy is an important adaptation to temperate climates because it prevents germination before the winter after fruit maturation. Thus, the plants emerge in the spring and have sufficient time to grow and to become hardy enough to resist the next winter cold period. Overcoming dormancy is necessary for seed germination.

To obtain good germination rates and early rootstock growth peach seeds can be planted after the winter or after artificial stratification, under temperatures around $5^{\circ} \mathrm{C}$ and adequate moisture characteristic of mild winter climates. Integument removal and hormonal treatments are also usual (García-Gusano et al., 2005). The low temperatures associated with moisture modify the equilibrium among growth inhibitors and promoters, resulting in germination (Webb et al., 1962). The content of growth promoters such as 
Ggibberellins and indolacetic acid increase during the stratification, while inhibitors such as abscisic acid decrease (Dias and Martin, 1972; Selim et al., 1998).

The growth inhibitors could be localized in several seed tissues, so that the seed dormancy could be caused by the integument, by the embryo or by both (Bewley, 1997; Foley, 2001). If seed dormancy is a function of embryo genotype, it can be used for the selection of low chilling genotypes. Selection based on seed dormancy may facilitate the cultivar improvement in mild winter climates, saving time and labor, and perhaps increasing efficiency of the cultivar improvement process.

Kester (1969) found variation in the stratification time necessary for germination between and within families of Prunus dulcis. This variation was attributed to genetic variation among the embryos, environment effects among layers during stratification (temperature, moisture and aeration), and maternal effects, due to different hormonal and nutritional supply or the environment during seed development. All these factors can affect the physiological process of the germination.

Seedlings emerging from insufficiently stratified seeds grow slowly and have short internodes and deformed leaves due to embryo inhibitors (Martínez-Gómes and Dicenta, 2001). Peach seed dormancy could be a function of the integument or the embryo. The dormancy caused by seed integuments is of a physical-hormonal nature (Mehanna and Martin,1985; Martínez-Gómes and Dicenta, 2001).

Although the integument seems to be less important to the peach seed dormancy than the embryo, its removal would be useful for breeding purposes because it originates from maternal tissue.

The physiological bases for the chilling requirement required to break peach seed dormancy and stimulate budbreak are considered to be similar. This means that seeds of low chilling requirement plants need less chilling to germinate than seeds of high chilling requirement plants (Kester, 1969).

Chilling requirements for breaking seed dormancy and allowing budbreak have been compared in several temperate species by studying the correlation between the chill necessity of seeds and the buds of their parent plants (Westwood, 1968; Kester, 1969; Pasternak, 1980; Mehlenbacher and Voordeckers, 1991; Wagner Júnior, 2007), and also among the seeds and their seedlings (Rodriguez and Sherman, 1985; Mehlenbacher and Voordeckers, 1991).

Maternal tissues (integument and endocarp) have been found to control seed germination of peach and other temperate species (Martinez-Gómes and Dicenta, 2001; García-Gusano et al., 2005), but the male parent effect on seed germination has been also demonstrated in almond (Kester, 1969; García-Gusano et al., 2005), almond $\times$ peach hybrids (Kester, 1969) and peach $\times$ nectarine (Rodriguez and Sherman, 1985). Kester (1969) did not find maternals effect on germination of almond seed derived of reciprocal crosses. Although the male parent did effect seed germination, there was no correlation between parent chilling requirement and seed dormancy.

In a previous work, Wagner Júnior et al. (2007) evaluated the influence of constant $\left(5\right.$ and $\left.10^{\circ} \mathrm{C}\right)$ and cycled $\left(5^{\circ} \mathrm{C} / 10^{\circ} \mathrm{C}\right.$ alternated every two and every seven days) temperatures on overcoming dormancy of seeds of the peach 'Campinas-1'. They concluded that all treatments were efficient in breaking seed dormancy, but the germination began later under $5^{\circ} \mathrm{C}$ constant temperature and was faster under constant $10^{\circ} \mathrm{C}$ and under $5^{\circ} \mathrm{C} / 10^{\circ} \mathrm{C}$ alternated every two days. Although the chill unit accumulation was higher at the constant $5^{\circ} \mathrm{C}$ treatments, probably $10^{\circ} \mathrm{C}$ was more adequate for germination after overcoming dormancy. Thus alternating temperatures can be an efficient method to discriminate seeds with different chilling requirement because interchanging temperatures are favorable for overcoming dormancy and stimulating germination.

The aim of this work was to study the effect of embryo genotype on the chilling requirement for peach seed germination. 


\section{पMATERIALS AND METHODS}

The seeds evaluated were obtained from the low chilling requirement peach 'Campinas-1' that was either open-pollinated or crossed with the high chilling requirement cultivar 'Miraflores'. 'Campinas-1' is the lowest chilling requirement genotype available in the peach germplasm collection of the Federal University of Viçosa (UFV). Pollen of 'Miraflores', a high chilling requirement genotype, were introduced from the Aula Dei Experimental Station (EEAD/CSIC), in Zaragoza, Spain.

The crosses were made at the experimental farm of UFV located in Araponga MG, Brazil (20 $40^{\prime} \mathrm{S}, 42^{\circ} 31^{\prime}$ W, $885 \mathrm{~m}$ above sea level). The pollen of 'Miraflores' was collected in March 2007 in Spain, stored under refrigeration $\left(0^{\circ} \mathrm{C}\right)$ and used to pollinate 'Campinas-1' in July 2007 in Brazil. The crosses were done after the removal of anthers and petals near to anthesis.

The seeds were collected near the time of fruit maturity in November 2007, when the ground color of the skin changed to yellow (Delwiche and Baungardner, 1985). The pits were removed from the mesocarp and cleaned. The seeds were removed of the endocarp in January 2008, treated with fungicide solution (Benlate $500-15$ g.L ${ }^{-1}$ ), conditioned in sealed, transparent, polyethylene bags containing moist germination paper. The bags were placed in a dark growth chamber with temperature alternating between 5 and $10^{\circ} \mathrm{C}$ every two days (Wagner Júnior et al., 2007). The germination paper moisture was maintained in the bags by adding water with a syringe. The seeds were examined daily to register the beginning of germination. The emergence of the radicle was defined as the beginning of germination.

The experiment was carried out in a complete randomized design, with twelve replications and five seeds per parcel.

A regression analysis was performed on germination percentage data. The germination percentages were grouped into classes of four days each.

\section{RESULTS AND DISCUSSION}

Seeds derived from open-pollinated 'Campinas-1' began to germinate twenty days after stratification and reached about $80 \%$ of total germination in the following two days. Germination of the 'Campinas-1' $\times$ 'Miraflores' progeny seeds began after 25 days of stratification and reached $80 \%$ of total germination after 40 days of stratification (Fig. 1).

The faster germination of the seeds of open-pollinated 'Campinas 1' indicate a strong effect of the embryo genotype on the chilling requirement for overcoming dormancy. Although the seeds were not obtained after artificial self pollination, we assumed a predominance of self pollinations and the surrounding cultivars present in the collection were all low or very low chilling requirement genotypes. So the low chilling requirement of the embryos of the seeds obtained of the open-pollinated 'Campinas -1 ' was expected even with some crossing with adjacent cultivars.

The results were similar to those obtained by Wagner Júnior et al. (2007). They observed germination beginning at 23 days after stratification and $80 \%$ germination after 26 days with 'Campinas 1' seeds kept under alternating 5 and $10^{\circ} \mathrm{C}$ temperatures.

The seeds of the open-pollinated 'Campinas-1' germinated over a short period of time (from the $20^{\text {th }}$ to the $27^{\text {th }}$ day), whereas the seeds from the controlled crosses had a wider interval of germination time $\left(24^{\text {th }}\right.$ to $47^{\text {th }}$ day) (Fig. 2), showing the quantitative effect of the seed dormancy trait.

Similar studies including the self pollination of the high chilling requirement genotypes (not available in our conditions) would help to understand the genetics of seed dormancy. Comparisons of the chilling requirements of the plants originating of seeds selected with low and high chilling requirements for overcoming dormancy would make it possible to evaluate the use of this methodology as a selection procedure.

Correlation of results obtained under controlled conditions with bud break chilling requirement of seedlings in the field would allow the selection of low chilling requirement genotypes based on seed dormancy.

Kester (1969) found approximately normal distributions of chilling requirements 
Ifor overcoming seed dormancy in most of the hybrid progenies among almond (Prunus dulcis) and peach, but in some cases the offspring had requirements similar to the higher requirement parents. Rodriguez and Sherman (1985) did not find a correlation among the mean chill requirement for budbreak of the parents and the chill requirement for $80 \%$ germination of the seeds obtained among female parents requiring 330 to 450 chill units and male parents requiring 200 to 400 chill units.

Wagner Júnior (2007), studying $F_{1}$ peach progenies found significant correlations among chill units for overcoming seed dormancy (50 and 100\% germination) with $50 \%$ vegetative bud break $\left(\mathrm{r}=0,48^{* *}, 0,50^{*}\right.$, respectively). The low correlation coefficients, although significant, indicate segregation of chilling requirement alleles within the seeds (collected from $\mathrm{F}_{1}$ hybrid plants) and could be screened based on seed dormancy. High correlation coefficients would indicate, in this case, maternal effects on seed dormancy.

Kester (1969) found different germination curves and times to reach $50 \%$ seed germination of one almond genotype crossed as female with five male parents that had different flowering times. García-Gusano et al. (2005) also verified the influence of male parents on the chilling requirement to overcome dormancy of almond seeds with the endocarp. Nevertheless there was no established correlation between the flowering time of the male parent and the chilling requirement to overcome seed dormancy.

Rodriguez and Sherman (1985) crossed two peach female genotypes (requiring 200 and 400 chill units) with twelve male parents (requiring 300 to 450 chill units) and observed male parent effects on the chilling requirement of the offsprings, but not on the seed germination. They considered that the chilling requirements for overcoming seed dormancy and for bud break could have different genetic controls. Dicenta et al. (2005) studied the possibility of the selection of high chilling requirement almond genotypes based on the chilling requirement for seed germination but concluded that the correlation among seed dormancy and bud chilling requirements were too low, although significant. In both of the works above, the seeds were stratified at relatively constant temperature: 5 to $6^{\circ} \mathrm{C}$ by Rodriguez and Sherman $(1985)$ and at $7^{\circ} \mathrm{C}$ by Dicenta et al. (2005). It is possible that the low temperatures prevented germination even after overcoming dormancy. This made the screening more difficult because the parents had more similar chilling requirements than the parents tested in this work. The adoption of alternate temperature by stratification would probably permit more sensitive screening.

The strong effect of the embryo genotype on the chilling requirement for overcoming seed dormancy encourages the use of the selection of low chilling requirement genotypes based on seed dormancy. Although the effect of the embryo genotype on the seed dormancy has been well demonstrated in this work, to be efficient, the selection based on seed dormancy must be able to screen less divergent genotypes. The alternating temperatures seem to be useful for this screening method because it interchanges temperatures favorable for overcoming dormancy with temperatures favourable to begin seed germination.

\section{ACKNOWLEDGEMENTS}

Thanks to CNPq, CAPES and FAPEMIG for financial support.

\section{Literature Cited}

Bewley, J.D. 1997. Seed germination and dormancy. The Plant Cell 9:1055-1066.

Delwiche, M.J. and Baungardner, R.A. 1985. Ground color as a peach maturity index. J. Amer. Soc. Hort. Sci. 100:53-57.

Diaz, D.A. and Martin, G.C. 1972. Peach seed dormancy in relation to endogenous inhibitors and applied growth substances. J. Amer. Soc. Hort. Sci. 97:651-654.

Dicenta, F., Garcia-Gusano, M., Ortega, E. and Martínez-Gomés, P. 2005. The possibilities of early selection of late-flowering almonds as a function of seed germination or leafing time of seedlings. Plant Breeding. 124:305-309.

Foley, M.E. 2001. Seed dormancy: an update on terminology, physiological genetics, and quantitative trait loci regulating germinability. Weed Science. 49:305-317. 
[García-Gusano, M., Martínez-Gómes, P. and Dicenta, F. 2005. Pollinizer influence on almond seed dormancy. Sci. Hort.104:91-99.

Kester, D.E. 1969. Pollen effects on chilling requirements of almond and almond-peach hybrid seeds. J. Amer. Soc. Hort. Sci. 94:318-321.

Lesley, J.W. 1944. Peach breeding in relation to winter chilling requirements. Proc. Amer. Soc, Hort. Sci. 45:243-250.

Martínez-Gómes, P. and Dicenta, F. 2001. Mechanisms of dormancy in seeds of peach (Prunus persica (L.) Batsch) cv. GF305. Sci. Hort. 91:51-58.

Mehanna, H.T. and Martin, G.C. 1985. Effect of seed coat on peach seed germination. Sci. Hort. 25:247-254.

Mehlenbacher, S.A. and Voordeckers, A.M. 1991. Relationship of flowering time, rate of seed germination and time of leaf budbreak and usefulness in selecting for lateflowering apples. J. Amer. Soc. Hort. Sci. 116:565-568.

Pasternak, G.P. and Powell, L.E. 1980. Chilling requirements of apple seeds from cultivars having low and high chilling requirements for shoot growth. HortScience 15:408.

Rodriguez, A.J. and Serman, W.B. 1985. Relationships between parental, seed and seedling chilling requirement in peach and nectarine. J. Amer. Soc. Hort. Sci. 110:627-630.

Selim, H.H., Omaima, A.K., Wafaa, A.E. and Tahany, Y.H. 1998. Physiological studies on propagation of Nemaguard peach seeds. Arab Univ. J. Agri. Sci. 6:249-266.

Wagner Júnior, A. 2007. Seleção de pessegueiro adaptado ao clima subtropical. 108p. (Thesis - Universidade Federal de Viçosa).

Wagner Júnior, A., Silva, J.O.C., Santos, C.E.M., Pimentel, L.D. and Bruckner, C.H. 2007. Stratification of peach seeds in constant and cycled temperature. Revista Brasileira de Agrociência 13:39-42.

Webb, D. P., Van Staden, J. and Wareing, P.F. 1973. Seed dormancy in Acer: changes in endogenous cytokinins, gibberellins and germination inhibitors during the breaking of dormancy in Acer saccharum 'Marsh'. J. Exp. Botany 24:105-116.

Westwood, M.N. and Bjornstad, H.O. 1968. Chilling requirements of dormant seeds of 14 pear species as related to climatic adaptation. Proc. Amer. Soc. Hort. Sci. 92:141149. 


\section{Figures}

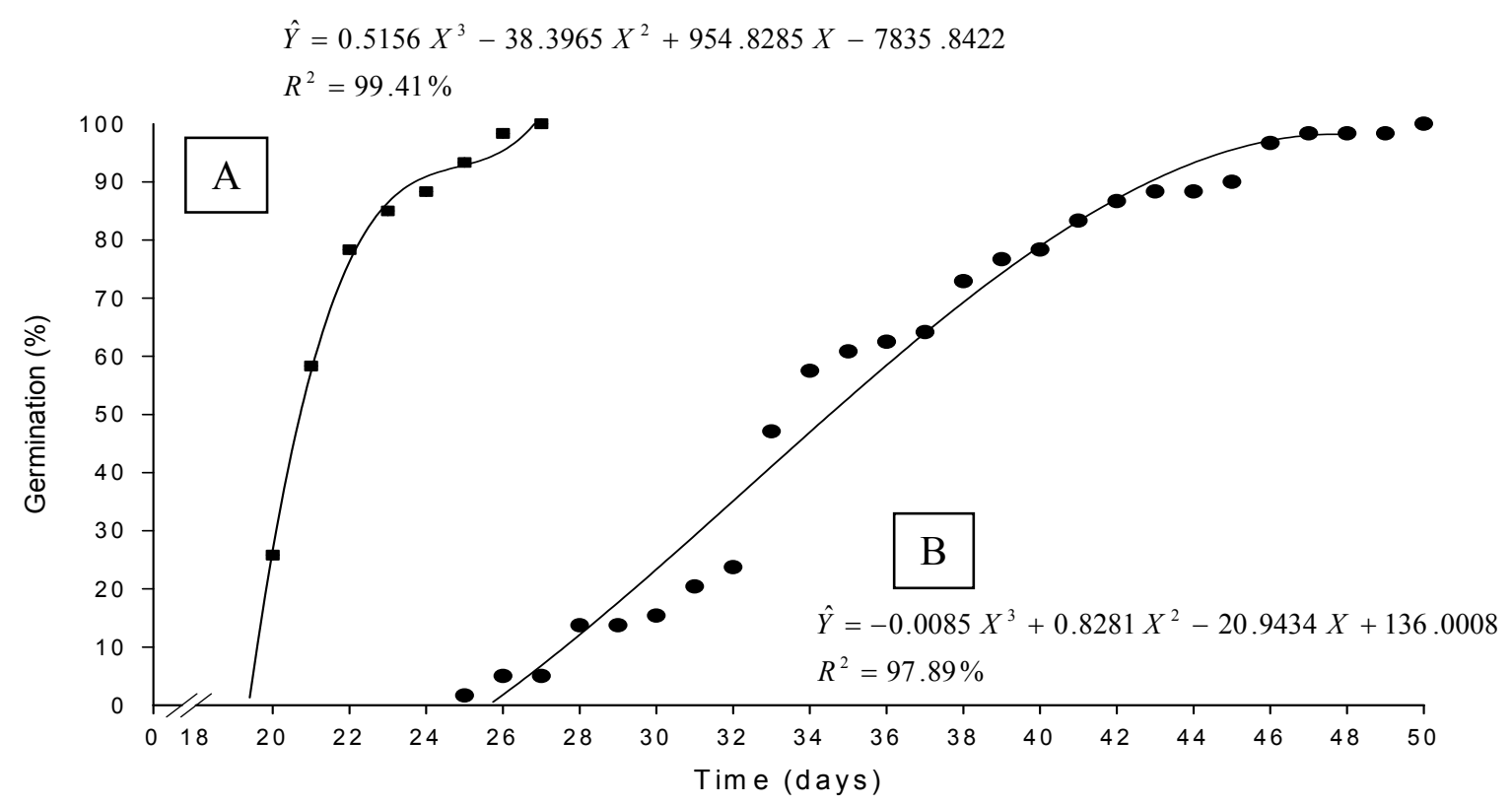

Fig. 1. Germination of seeds of the peach 'Campinas 1' open-pollinated (A) and crossed with 'Miraflores' (B), stratified under alternated temperatures $\left(5\right.$ and $10^{\circ} \mathrm{C}$ every two days). 


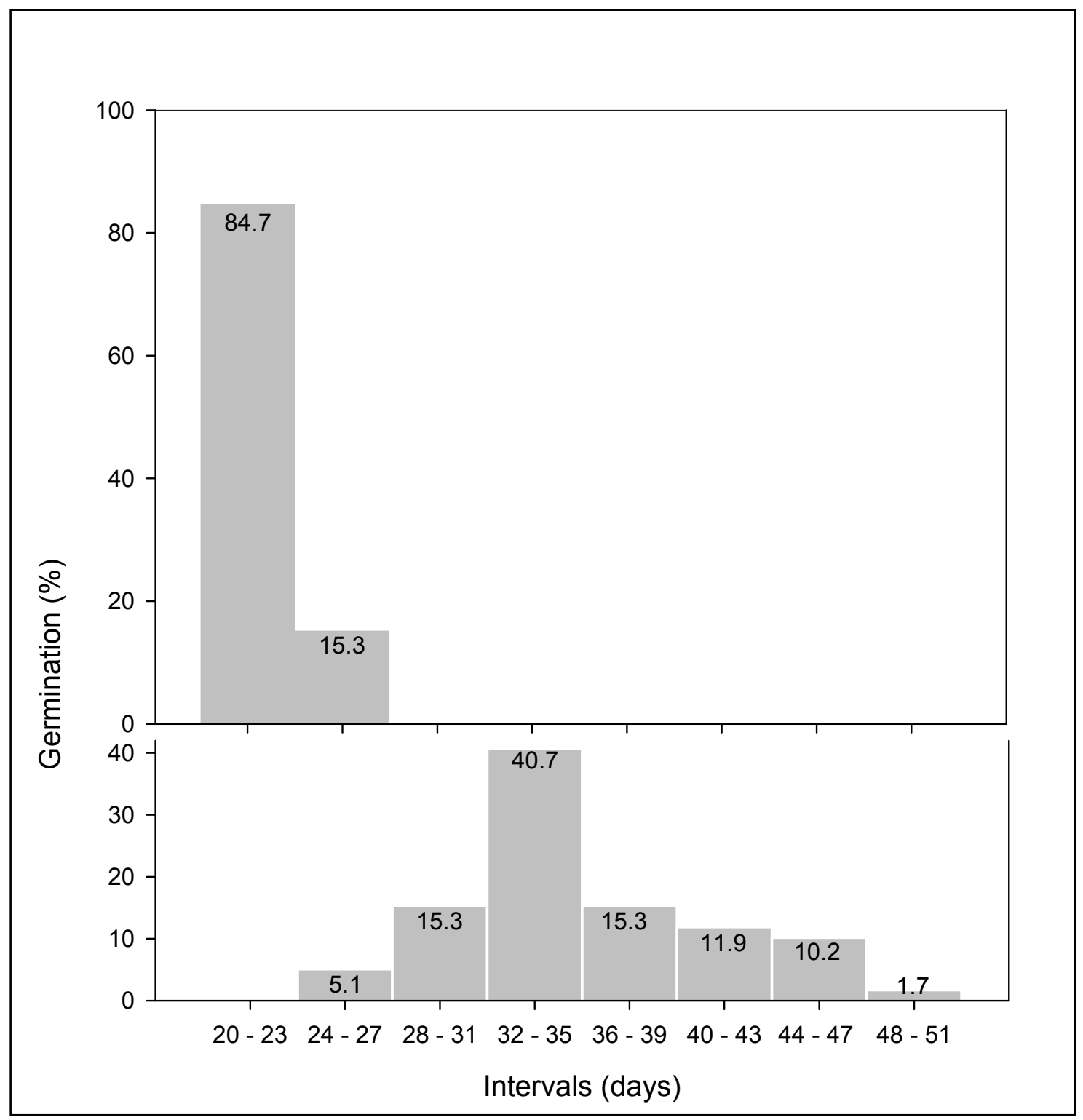

Fig. 2. Distribution of the germination of seeds of the peach 'Campinas 1' open-polinated (above) and crossed with 'Miraflores' (under), stratified under alternated temperatures (5 and $10^{\circ} \mathrm{C}$ every two days). 